\title{
Formalism, rationality, and evidence: the case of behavioural economics
}

\author{
SHEILA C. DOW \\ University of Stirling
}

\begin{abstract}
Mark Blaug played a central role in the development of the field of the methodology of economics, alongside his theoretical work and contributions to the history of economic thought. The purpose, in this article, is to focus on his contributions to the topic of 'formalism in economics', in relation to his methodological commentaries on the Popperian and Lakatosian approaches to the philosophy of science. In Blaugian spirit, the discussion is related to economic theory and draws on the history of economic thought. The argument focuses on the troublesome interface between theoretical and applied economics in mainstream economics. The article includes, as a case study, an assessment of new behavioural economics in Popperian and Lakatosian terms. The conclusion is that such an appraisal exercise-i.e., whether the research programme is progressive or degenerative-is clouded by the interface between the form of empiricism promoted by Popper and Lakatos and the methodological framework of mainstream economics. No conclusion is feasible independent of methodological approach.
\end{abstract}

Keywords: behavioural economics, formalism, experimental evidence, economic rationality, empiricism, falsificationism, methodology of research programmes

JEL Classification: A11, B20, B41, D03

Mark Blaug was well known both for his promotion of a Popperian/Lakatosian approach to the methodology of economics and for his critique of mathematical formalism. While his thinking evolved over the years-as you would expect for such a subtle thinker and prodigiously-well-read scholar-these were consistent themes over his long years of leading and contributing to thinking on methodology.

Blaug's stance directly addressed the emergence of a juxtaposition during the twentieth century between two conflicting trends in

AUTHOR's NoTE: I am grateful to Peter Earl, Luis Mireles-Flores, two anonymous referees, and participants in the SCEME Seminar in Tribute to Mark Blaug in Glasgow on 26 March 2012 for helpful comments and suggestions. 
economics: on the one hand the idea that theory should be appraised by reference to the evidence, and on the other hand a form of theory which eluded definitive direct testing. Furthermore, of the two trends it was the second which had become increasingly dominant in economics.

In addition to Blaug's philosophical interest, this juxtaposition has attracted particular attention in the field of experimental economics and its relations with new behavioural economics. The empirical results of experimental economics at times seem to falsify key elements of pure theory in mainstream economics. Yet, amending theory in order to take this into account, particularly with input from psychology, has run up against the strictures of mathematical formalism.

In the Preface to the second edition of The methodology of economics (1992 [1980]), Blaug notes that he had contemplated adding material on new developments in economics, such as experimental economics. But he had decided against this, based on his "disinclination to rush in where angels fear to tread" (Blaug 1992, xii). Still this is what-with some trepidation-is proposed for the present contribution.

The financial crisis has provided new impetus to behavioural economics, in the search for an explanation for events which would seem to constitute massive falsifying evidence to a body of theory which presumed markets to be efficient and equilibrating. In this article, we will consider the extent to which new behavioural economics satisfies the Lakatosian criterion for a progressive research programme, namely the capacity to predict novel facts. More generally, we will consider how far the developing field of behavioural economics addresses Blaug's critique of formalism in mainstream economics.

In what follows, a brief account will be given of Blaug's Popperian/Lakatosian methodology in relation to his views on the formalisation of economic theory. We will then explore the tensions which have persisted in mainstream economics between pure theory and applied economics. In considering how mainstream economics has evolved in recent decades-including paying more attention to experimental evidence which seems to shed light on the financial crisis-we will draw on Blaug's views about economic rationality; a notion which is central to the evolution of new behavioural economics. We will then consider the methodological issues surrounding experiments in economics and how far the use of experimental evidence addresses Blaug's critique of mainstream economics. 


\section{BLAUG'S POPPERIAN METHODOLOGY}

Blaug's methodological position is summed up by him in the final sentences of both editions of his Methodology of economics:

the ultimate question we can and indeed must pose about any research program is the one made familiar by Popper: what events, if they materialized, would lead us to reject that program? A program that cannot meet that question has fallen short of the highest standards that scientific knowledge can attain (Blaug 1992, 248). ${ }^{1}$

One of the hallmarks of Blaug's methodology was his espousal of falsificationism. Blaug observed that economists paid lip-service to falsificationism while practising verificationism when seeking empirical support for theoretical conclusions. Blaug's criticism of the disparity between what economists said they were doing and what they were actually doing was a contribution in itself, to which we will return below.

Blaug was careful not to espouse naïve falsificationism, being well aware of the ambiguities of testing procedures such as the DuhemQuine problem. Any hypothesis being tested incorporates a collection of sub-hypotheses, both theoretical and in terms of mathematical expression and selection of data. It is therefore difficult to identify what precisely has been falsified by an empirical test. Popper himself had been well aware of these ambiguities, proposing a series of conventions for good scientific practice to discourage 'immunising stratagems' which would allow scientists to maintain theories in the face of falsifying evidence. Ambiguities in testing also result from the openness of physical systems with respect to observation. Popper (1982) argued that the process of observation was performative, itself changing the physical world; he gives the example of the drawing of a map of the world, which by being created changes the physical reality the map is designed to represent. Like Popper, Blaug was not a purist: "we want to gain knowledge of the world, even if it is only fallible knowledge" (Blaug 1992, 20). Nevertheless he was adamant that, for theory to be worth having, it had to be able to stand up to empirical evidence, which also meant that it could fall by evidence.

\footnotetext{
${ }^{1}$ Richard Lipsey recalls that-in conversation-Mark Blaug said he would be happy with a less stringent but more tractable requirement, namely that economists be prepared to specify what evidence would conflict with their theories (it being a necessary condition for a theory to have empirical content that it not be consistent with all possible observations).
} 
But the practice of verificationism had been given some methodological respectability by Lakatos (1970), who sanctioned disregard of contrary evidence on 'infant-industry' grounds as theory was developed, as well as appearing to sanction the protection of 'hard-core' principles from testing. Similarly, Blaug discusses how Popper himself allowed for degrees of corroboration (rather than a dualistic divide between falsification and verification). Blaug saw the subsequent popularity of Kuhnian ideas as an extreme version of this-a complete relativism, without any extra-paradigmatic criteria for appraisal. Blaug $(1992,42-47)$ was quite explicit that his methodological position was monist-it was possible and desirable to establish one best set of standards for appraisal. He thus lauded Lakatos's criterion of appraisal: the capacity to predict novel facts (see further Blaug 1991).

\section{THE RISE OF FORMALISM IN NEOCLASSICAL ECONOMICS}

Blaug maintained his critique of economics as not following Popper's proposed conventions for robust empirical testing. But the different problem of the absence of testing altogether increasingly became the focus of this criticism. By formalism Blaug meant the prioritising of the form of a theory over its content. That form need not be mathematical, although that is the formalism most evident in mainstream economics (Blaug 1999, 258). Where Blaug gave the highest priority to empirical appraisal-through which theories might be rejected-formalists normally treat empirical testing merely as something which might be done in principle or-in the extreme-as irrelevant (see Hahn 1981). Blaug (1999) charted the rise of formalism in mainstream economics in the second half of the twentieth century. General equilibrium theory, a particular type of formalism, had come to dominate the discipline. It employed a deductivist mathematical approach, built on a set of axioms concerning rational individual economic behaviour.

During this period, theorising and testing were increasingly being treated as separate activities, in spite of Popper's proposed conventions (Blaug 1999). Popper had argued for theorising to evolve by a process of conjecture and refutation, i.e., of testing successive narrow hypotheses against facts, with the outcome influencing the formulation of future conjectures. While formalism had encouraged ever more reductionism in general equilibrium theory, the axioms were taken to be self-evidently true. Further, any testing of propositions deduced from the axioms was riddled with the Duhem-Quine problem. If the data appeared to falsify 
the theory, what exactly had been falsified? Indeed it was difficult to discriminate between theories empirically, allowing the dominance of formal theory to persist.

Rational expectations theory addressed this bifurcation head on by defining all actual states as equilibrium states. Hence, not only did economists engage in empirical estimation and prediction with respect to formal theory, but so, effectively, did economic agents as well. While Sargent in particular struggled to deal with the circularity involved in this idea, the logical issues were never resolved in such a way that the theory would meet the deductivist-axiomatic requirements of general equilibrium formalism as well as the empirical estimation procedures that were internal to the theory and the basis for prediction (Sent 1998). While apparently falsificationist, the approach was never overtly dropped on the basis of its unimpressive prediction record, although it was not pursued further. Nevertheless, rational expectations remain embedded in mainstream macroeconomic theory.

But more recently there has been a different type of confrontation between pure theory and applied work. The rationality principle (constrained optimisation based on the rationality axioms), and thus the formalist structure itself, have been the subject of empirical challenge by experimental evidence. Blaug (1992, 232-233) noted that the anomalies which arose from experimental evidence had been widely dismissed as random perturbations at the micro level. But this is no longer the case. Since then the body of experimental evidence has grown considerably, as has the body of theory in new behavioural economicsto be distinguished from the old behavioural economists (see Sent 2004). A major impetus has been the financial and economic crisis, an event which could reasonably be regarded as an anomaly on a grand scale. It had proved difficult to settle the empirical status of the efficient markets hypothesis and subjective expected utility theory (for reasons encapsulated by the Duhem-Quine problem) but the crisis added weight to those who questioned their validity. In particular, aggregative evidence from financial markets suggested that there were systematic deviations from the results implied by the efficient markets hypothesis, which was founded on the rationality principle (Shiller 2000). These deviations could be explained by psychological factors for which experimental evidence provided support. Akerlof (2002) generalised this approach to behavioural macroeconomics. 
Blaug (1992, 233) had concluded that, while only a naïve falsificationist would abandon the mainstream approach purely on the grounds of such anomalies, abandonment was made possible by such alternatives as prospect theory and Herbert Simon's notion of bounded rationality. The implication was that there might be a new progressive research programme in the making. But there has also been a process of retrenchment (which could be classified as immunising stratagems) as mainstream economists have attempted to explain the crisis in terms of constraints on the operation of an equilibrating market system (restrictions on competition, asymmetric information, and/or distorted incentives). Even among behavioural economists there has been a reluctance to depart significantly from the standard framework. Camerer and his colleagues introduce their substantial behavioural economics reader as follows:

At the core of behavioral economics is the conviction that increasing the realism of the psychology underlying economic analysis will improve the field of economics on its own terms-generating theoretical insights, making better predictions of field phenomena, and suggesting better policy. This conviction does not imply a wholesale rejection of the neoclassical approach to economics based on utility maximization, equilibrium, and efficiency. The neoclassical approach is useful because it provides economists with a theoretical framework that can be applied to almost any form of economic (and even noneconomic) behavior, and it makes refutable predictions (Camerer, et al. 2004, 1; emphasis in the original).

Yet Berg and Gigerenzer $(2010,134)$ criticise new behavioural economics precisely for retaining the standard framework, highlighting the consequent 'very partial commitments to empirical realism'. In what follows we consider how far new behavioural economics comes up to Blaug's methodological empirical realist standards. We consider this question in terms of the tension in mainstream economics between empirical testing and formalism.

\section{NEW BEHAVIOURAL ECONOMICS}

We have seen that new behavioural economics introduced psychology into economics on the realist grounds that there was evidence of behaviour which deviated from what was assumed in standard mainstream theory, that is, empirical anomalies. But to satisfy Blaug's criteria we want to see: a) that the response to these anomalies was 
theoretical developments which are not just ad hoc adjustments, b) the capacity to predict novel facts or provide novel explanations, c) an abductive approach to theorising such that theoretical developments are driven by reference to evidence, and d) an indication of what would cause behavioural economists to reject their own theories. How far does it live up to Camerer and his colleagues' (2004) own promise of generating refutable predictions, that is, to falsificationism?

Although not all of this evidence was experimental, and not all experimental economics feeds into behavioural economics, there is nevertheless a significant overlap between the two (see Sent 2004). This inter-relationship was reflected in the award of the 2002 Nobel prize jointly to Kahneman for his contributions to behavioural economics and to Smith for his contributions to experimental economics. The experimental evidence appeared to falsify either the rationality axioms or the presumption of optimising behaviour which formed part of the hard core of the mainstream research programme.

Conventionally, as part of the hard core, the rationality principle had been regarded as being exempt from falsification; rationality could be regarded as a metaphysical principle. While Popper saw theory as being built on conjectures rather than axioms, he had supported this exemption from testing for the rationality principle, allowing a significant element of commonality between Popper and Lakatos when it came to economics. Blaug $(1992,231)$ explained such a surprising stance in terms of Popper's lack of understanding of the significance of the rationality principle for economics. Further, he argued that Popper had not appreciated the significance of the auxiliary hypotheses attached to the assumption of rationality (such as full information) which were adopted to make the principle theoretically tractable.

But what does the experimental evidence signify? Some have argued that definitive empirical tests of the rationality axioms are not feasible (Blaug 1992, 231). If tested by means of experiments, the results would be ambiguous because of the Duhem-Quine problem. It would be impossible to test the rationality principle independently of assumptions about the stability of preferences, for example. But over the last decade experimental economics has become increasingly sophisticated in devices (such as double-blind experiments) to ensure that the hypotheses being tested are sufficiently narrow and precise, and the tests themselves so well-organised in efforts to yield clear results, that they can be said to adhere to Popper's proposals for dealing 
with the Duhem-Quine problem (see, e.g., Berg, et al. 2005). In particular, efforts have been made in designing experiments to isolate individuals from social interaction in order to observe self-interested individualistic behaviour.

But such a stratagem may be interpreted in terms of too much isolation. The intention is to make the experiments accord more precisely to the theoretical framework based on methodological individualism and the rationality principle, but that means the experiments are not reflecting evidence of actual behaviour in the different framework of reality (see further Hargreaves Heap 2009). If, for example, individuals are in fact other-regarding, then it is not clear how experimental conclusions about isolated behaviour can explain actual behaviour. Some experimental evidence (as in the ultimatum game) indicates an other-regarding aspect of individual behaviour which can be taken as falsifying evidence with respect to the standard rationality axioms, and also as limiting the relevance of evidence based on experiments designed to abstract from otherregarding behaviour. Other-regarding behaviour-in the form of mass psychology or herd behaviour-provides an important behavioural explanation for the financial crisis (see, e.g., Kirman 2011).

Others have pointed to logical problems in interpreting experimental evidence which aims to identify deviations from a rational optimising benchmark. For example, the presumption that agents rationally optimise on information in order to rationally optimise in choice situations has been shown to collapse in an infinite regress (Winter 1964; Cohen and Dickens 2002). More generally, Berg and Gigerenzer (2010) classify rational optimisation as 'as-if' behaviour, and call into question the validity of interpreting experimental evidence and results with respect to a framework where significant 'as-if' assumptions are retained. Taking prospect theory as an example, they point to its limited departure from the standard framework in that the experiments presume that risks can be quantified and manipulated in a sophisticated way. These presumptions about the capacity for knowledge appear to be logically inconsistent with the behavioural theory that agents employ heuristics in order to cope with cognitive limitations (see Tversky and Kahneman 1974; Kahneman and Tversky 1979). Such limitations were a core element of Simon's (1955) earlier development of the concept of bounded rationality. 
Cognitive limitations are an important feature of behavioural economics explanations for behaviour which appears to be otherregarding even in a methodologically-individualistic framework. But in fact much of behavioural economics retains the individual rationality framework. Thus, for example, individual behaviour may be like herd behaviour, but only in the sense of putting undue emphasis on past trends (Bikhchandani and Sharma 2001). Shiller's (2000) feedback theory uses the rationality framework as a benchmark for classifying such behaviour as irrational. Similarly, instability in the real economy may be seen as the result of financial instability (exaggerated amplitude of asset price deviations) which arises from self-fulfilling beliefs, confusingly dubbed 'animal spirits'. This literature explains such beliefs in terms of Keynes's 'beauty contest model' of expectations formation. But, even if expectations deviate from what rationality would predict, the individual decision-maker is depicted as forming optimal expectations given cognitive limitations. In any case, for some contributors, the nature and role of cognitive limitations are peripheral to the explanation of financial instability. The important explanatory factor is an exogenous disturbance to beliefs, which can just as easily be explained by sunspots (see, e.g., Farmer and Guo 2004). Retaining the basic rational choice framework is given priority over the explanation of actual behaviour.

The input of psychology into behavioural economics also takes the form of specifying unconventional preferences to which rational choice is applied. Thus, within representative agent models in prospect theory, for example, scope is given for unconventional preferences such as loss aversion (Kahneman and Tversky 1979). This explains behaviour which otherwise appears to be irrational. Similarly, heterogeneous agent models may allow for different groups of market participants with different preferences. In particular, non-professionals may be guided by sentiment, while professional arbitrageurs are guided by rationality. Instability may emerge if sentiment drives markets in a particular direction, although arbitrageurs will normally ensure a return to equilibrium (Baker and Wurgler 2007). But, as advocated by Robbins (1932), the source of preferences is not explored; it is taken as given (see further Binmore and Shaked 2007).

\section{PROGRESSIVE OR DEGENERATING RESEARCH PROGRAMMES}

As Sent (2004) argues, what distinguished new behavioural economics from old behavioural economics is that the reference point for the 
former is always the standard rational-choice framework. Where old behavioural economists absorbed the evidence of deviations from the rational-choice model and developed an alternative framework accordingly, new behavioural economists accepted the rational-choice framework as their hard core, but amended its auxiliary hypotheses by modifying models to allow for (limited) cognitive limitations and unconventional preferences (Earl 2010). As Kahneman (2003, 1469) put it: "Theories in behavioural economics have generally retained the basic architecture of the rational model, adding assumptions about cognitive limitations designed to account for specific anomalies". Further, anything which cannot be explained in terms of rationality is dualistically classified as irrationality (Altman 2004). This is clearly shown by Akerlof and Shiller (2009); the behavioural explanations they offer for evidence which challenges mainstream theory explicitly refer to such behaviour as either 'irrational' or 'non-economic'. The Lakatosian framework thus seems to be successful in providing a good account of new behavioural economics as protecting the hard core rationality principle. But, while this may have helped in communicating new behavioural economics ideas to mainstream economists, it leaves behavioural economics without its own coherent theoretical foundation (Cohen and Dickens 2002).

How well does new behavioural economics stack up in terms of Lakatos's appraisal criteria of predicting novel facts and avoiding ad hoc adjustments? There has been a range of critiques of new behavioural economics on the grounds that it can provide ex post explanations for behaviour, but falls short on prediction (see, e.g., Binmore and Shaked 2007). Similarly, Cohen and Dickens introduce their argument for an alternative theoretical framework (evolutionary psychology) as follows,

the policy influence of [behavioural economics] is limited by its inability to predict circumstances in which anomalous behavior will arise (other than in those sorts of circumstances in which it has been observed before) or how it will respond to policy changes (Cohen and Dickens 2002, 335).

They then proceed to discuss bounded rationality as an ad hoc adjustment.

Mark Blaug (1992) encourages consideration of whether a research programme is progressive or degenerating by means of comparison. As Backhouse $(1991,412)$ points out, a novel fact could be understood as a 
new explanation of an existing fact. Thus, while the financial crisis as experienced from 2007 was not a novel event, new behavioural economics provided a new explanation. But in mainstream economics it was only novel to analyse financial crises as systemic with reference to expectations formation and decision making. Other approaches already offered this kind of explanation, inviting direct comparison between new behavioural economics and these alternative explanations. It is crucial that these alternative explanations arose from different methodological frameworks, so direct comparison as advocated by Blaug is impossible. Not only are there different criteria for judging what is a novel fact and what is a satisfactory explanation, but different meanings are ascribed to both concepts and evidence (see Dow 2012, chapter 1).

As an example of an alternative explanation, old behavioural economics already had well-developed theories of decision-making based on satisficing rather than optimising and using heuristics in order to address cognitive limitations-most of which is precluded by the mainstream rational optimising framework. Berg and Gigerenzer (2010) draw attention particularly to the incompatibility between the gross substitution assumption of the mainstream framework and the adoption of lexicographic preferences, for which there is substantial evidence. The concept of bounded rationality spawned a rich and complex body of thought among old behavioural economists (Fiore 2011). As another example, post-Keynesian economics already had a macroeconomic theory of financial instability which combined a theory of uncertainty (only partly due to cognitive limitations) with a theory of financial structure (Minsky 1982). This theory could not predict the timing of the financial crisis, but did account for how financial fragility was increasing in the years leading up to 2007 creating the conditions for a crisis. Both approaches are logically consistent. The limitations to knowledge which underpin the core concepts of both bounded rationality and uncertainty are incorporated into an open-system understanding of social systems. Rather than being calculative optimisers, agents cope by adopting heuristics, adopting conventional knowledge, following conventional behaviour in practices and routines (which are not necessarily sensible), and satisficing. In this way, theory is consistent with its ontological and epistemological foundations, which contrasts with the internal consistency criterion within a deductivist mathematical framework. 
Nevertheless, can the new behavioural economics research programme be seen as progressive at least within mainstream economics? It addresses anomalies which have been found, not only in experimental evidence but also in more conventional econometric evidence, with new theories. Thus Rabin and Thaler (2001) challenged the subjective expected utility theory with an alternative explanation for risk aversion which accorded more with the experimental evidence. Shiller (2000) had identified excess swings in asset prices compared to what was predicted by the efficient markets hypothesis, and explained them in terms of the psychology of information gathering and expectations formation: undue emphasis on trends, undue attention to media interpretations, and so on. Accordingly he developed feedback models to capture this behaviour (see Shiller 2003).

New behavioural economics includes elements which depart from the mainstream framework, as in some authors accepting limitations to global rationality (for a cataloguing of similarities and differences, see Earl and Peng 2012). Perhaps most tellingly, there is a willingness to pursue non-universal explanations, a feature reminiscent of old behavioural epistemology. Here we find some inconsistency between what new behavioural economists say in terms of adopting the standard framework and what they do. This echoes Blaug's observation that mainstream economists behave inconsistently with their professed falsificationism. It also echoes McCloskey's (1983) observation of the disparity between the formalist 'official discourse' of mainstream economics and the pluralist, context-specific 'unofficial discourse'. Lawson (1997) identifies inconsistency too, between the closed-system methodology of mainstream economics (which allows for theorising in terms of constrained optimisation) and any sense of the openness of real social systems. Were new behavioural economists to emphasise consistency with their observations of reality over the internal consistency (and universality) of the rational optimising framework, there would be much more scope for theoretical developments which are not ad hoc adjustments to existing theory. But by retaining the hard core of mainstream economics in the form of the rationality benchmark, even if not rationality itself, new behavioural economics is accepting constraints on its scope for progressive development. 


\section{THE RELATIVE PRIORITISATION OF THEORY AND EVIDENCE}

The insistence on a formalist approach to theory was the subject of Blaug's (1999) critique of mainstream economics. Nowadays more attention is being paid to evidence. But as I have shown, the way in which the formalist mainstream approach developed, with its benchmark of rational optimisation, constrains the way in which theory can evolve in response to new evidence. ${ }^{2}$ Being a deductivist approach, the axioms are of critical importance, so any modification requires general acceptance (not just local applicability) and feeds through into all theoretical results. Either the behavioural approach defines actual behaviour as rational by redefining the constraints, or the behaviour is redefined as irrational. Then the choice is whether to treat irrational behaviour as stochastic, which again does not challenge mainstream theory, or to theorise and model it. But how can that be achieved other than with a modified set of axioms? And what is more, how can a set of axioms incorporate irrationality?

Modelling heuristics, for example, could be an alternative, however some authors have recently reflected on the challenges posed by such approach (see, e.g., Goodhart 2008; De Grauwe 2010). More generally, there is a problem in trying to incorporate models of irrational behaviour into the general deductivist framework. As Blaug $(1992,233)$ points out, if the evidence suggests that behaviour departs from rationality in financial markets, then it must be presumed that it does so in other markets. This problem stems directly from mainstream methodology. A Lakatosian would be concerned at ad hoc adjustments such as introducing some constraints on market processes to explain anomalies. But within the mainstream framework what is regarded as ad hoc are theories which have only very localised application:

The enduring appeal of classical asset-pricing theory over the last several decades owes much to its success in forging a consensus around a foundational modelling platform. This platform consists of a core set of assumptions that have been widely-accepted by researchers working in the field as reasonable first-order descriptions of investor behaviour, and that-just as importantlylend themselves to elegant, powerful, and tractable theorizing.

If behavioural finance is ever to approach the stature of classical asset pricing, it will have to move beyond a large collection of

\footnotetext{
${ }^{2}$ Lawson (2009) and Dow (2012) have focused further on the deductivist, mathematical nature of this formalism.
} 
empirical facts and competing one-off models, and ultimately reach a similar sort of consensus (Hong and Stein 2007, 126).

The appraisal of new behavioural economics is thus conditioned by acceptance of the formalist mainstream methodological framework. It is this which challenges the value of partial theories which are not deterministic and drives the new behavioural economics agenda in the direction of ever more general formal theories of behaviour which are amenable to mathematical modelling. Within the mainstream framework, new behavioural economics would be theoretically progressive if it enhanced the existing body of theory by increasing its scope. It would be empirically progressive if it addressed evidence of anomalies and improved empirical prediction. But there is the potential for significant conflict between the two and, within the mainstream methodological framework, theoretical progressiveness is prioritised over empirical progressiveness. While the development of partial theories (feedback theories, prospect theory, and so forth) could be said to be empirically progressive, this is incompatible with trying to fit such theories into a general equilibrium framework deduced from the rationality axioms. As long as new behavioural economics accepts the mainstream framework, therefore, it is likely to become degenerative.

\section{CONCLUSION}

This discussion indicates that new behavioural economics falls short in Lakatosian terms. It could become a progressive research programme if it evolved through partial theories developed in an abductive interplay with evidence, an approach favoured by Blaug (1999). This is something which already exists in the old behavioural economics, as in Earl, Peng, and Potts's (2007) theory of instability in the housing market due to reliance on heuristics. Yet much of the academic success of new behavioural economics must be down to its self-presentation in relation to the rational optimisation framework (Earl and Peng 2012).

In making a Lakatosian comparative assessment of alternative research programmes, we run up against a meta-methodological problem. Considering Lakatos's prescriptive (as opposed to descriptive) framework once we move beyond mainstream economics is problematic in that Lakatos's approach itself is closely aligned with the mainstream approach to economics. What constitutes a novel fact (even in the form only of a satisfactory new explanation) and what constitutes an ad hoc 
adjustment depends on the particular understanding of the world, interpretation of facts and criteria for good theory (including consistency, as discussed above) which distinguish methodological frameworks. This was a key feature of Kuhn's discussion of paradigms which was dropped by Lakatos, for whom research programmes were directly empirically comparable. Just as the rationality principle is metaphysical and thus untestable, so too is the whole mainstream framework.

This problem is also evident when we consider Blaug's Popperian criterion, that economists should specify what evidence would lead them to reject a theory. Since theories are part of the complex structure of research programmes, which embody a particular understanding of and interpretation of reality and of what constitutes good theory, rejection ultimately has to be at the metaphysical level. This helps us understand the resistance by many economists to respond to the crisis by rejecting the mainstream framework (Earl 2010). But for some mainstream economists the crisis has shaken confidence in a research programme that assumes the capacity of markets to stabilise themselves. They are open to alternatives. Similarly, if austerity policies in a recession fuelled a supply-side boom then many Keynesians would lose confidence in their approach and seek alternatives. But within any research programme it is the overall approach which is decisive rather than individual theories. The discussion above has illustrated this in the case of behavioural economics.

Our consideration of new behavioural economics addresses Blaug's concern that theoretical appraisal be empirical in relation to his concern that too much priority was being placed on theoretical formalism. What we have seen is the blossoming of a relatively new area in mainstream economics which seems to successfully explain the financial crisis. But this is not a new research programme in the Lakatosian sense, since the hard core rationality principle was retained. Constraints on full information and on rational choice are explained by a more sophisticated representation of rationality or else as irrationality. This is a change in the protective belt. Nonetheless, there is a pressure on developing these theories in such a way as to make them more general through greater formalisation, that is, limiting the change to the protective belt by ensuring methodological compatibility with the mainstream. 
Genuinely alternative theoretical approaches, such as old behavioural economics and post-Keynesian economics, employ different methodological frameworks, thus constituting competing Lakatosian, research programmes. They adopt different stances with respect to the nature and meaning of theory and evidence from mainstream economics, but that is only relevant to the current argument inasmuch as it raises particular issues with a Lakatosian empirical criterion of appraisal. ${ }^{3}$ These different approaches are identified by different understandings of real-world processes and terminology from the mainstream research programme, so they have not been recognised (or indeed are not recognisable) as progressive from the mainstream perspective.

There is no independent way of making judgements about progression or degeneration across research programmes. While a Popperian/Lakatosian framework might encourage the idea of an empiricist alternative to formalism, we have seen that pure empiricism is unsatisfactory. A methodologist cannot be in a position to take an independent view on novel facts and ad hoc adjustments. This is not at all to say that any interpretation is as good as any other, but rather that there is no ultimate independent arbiter and therefore any position needs to be justified. Blaug was notably well-informed about and open to alternative approaches to economics. This is the best position from which to engage in constructive debate as to the merits of different theories and theoretical approaches.

\section{REFERENCES}

Akerlof, George A. 2002. Behavioral macroeconomics and macroeconomic behavior. American Economic Review, 92 (3): 411-433.

Akerlof, George A., and Robert J. Shiller. 2009. Animal spirits: how human psychology drives the economy, and why it matters for global capitalism. Princeton (NJ): Princeton University Press.

Altman, Morris. 2004. The Nobel prize in behavioral and experimental economics: a contextual and critical appraisal of the contributions of Daniel Kahneman and Vernon Smith. Review of Political Economy, 16 (1): 3-41.

Backhouse, Roger E. 1991. The neo-Walrasian research program in economics. In Appraising economic theories, eds. Neil de Marchi, and Mark Blaug. Cheltenham: Edward Elgar, 403-426.

Baker, Malcolm, and Jeffrey Wurgler. 2007. Investor sentiment in the stock market. Journal of Economic Perspectives, 21 (2): 129-151.

\footnotetext{
${ }^{3}$ Methodologists have raised a wide range of concerns with Lakatos's framework, to Blaug's (1991) dismay.
} 
Berg, Joyce, John Dickhaut, and Kevin McCabe. 1995. Trust, reciprocity, and social history. Journal of Games and Economic Behavior, 10 (1): 122-142.

Berg, Nathan, and Gerd Gigerenzer. 2010. As-if behavioral economics: neoclassical economics in disguise? History of Economic Ideas, 18 (1): 133-165.

Bikhchandani, Sushil, and Sunil Sharma. 2001. Herd behavior in financial markets. IMF Staff Papers, 47 (3): 279-310.

Binmore, Ken, and Avner Shaked. 2007. Experimental economics: science or what? ELSE Working Paper 263. London, UK.

Blaug, Mark. 1991. Afterword. In Appraising economic theories, eds. Neil de Marchi, and Mark Blaug. Cheltenham: Edward Elgar, 499-512.

Blaug, Mark. 1992 [1980]. The methodology of economics, or how economists explain. Cambridge: Cambridge University Press.

Blaug, Mark. 1999. The formalist revolution or what happened to orthodox economics after World War II? In From classical economics to the theory of the firm: essays in honour of D. P. O'Brien, eds. Roger E. Backhouse, and John Creedy. Cheltenham: Edward Elgar, 257-280.

Camerer, Colin F., George Lowenstein, and Matthew Rabin. 2004. Advances in behavioral economics. Princeton: Princeton University Press.

Cohen, Jessica L., and William T. Dickens. 2002. The role of nature versus nurture in determining economic outcomes: a foundation for behavioral economics. American Economic Review, 92 (2): 335-338.

De Grauwe, Paul. 2010. The scientific foundation of dynamic stochastic general equilibrium (DGSE) models. Public Choice, 144 (3-4): 413-443.

Dow, Shelia C. 2012. Foundations for new economic thinking. London: Palgrave Macmillan.

Earl, Peter E. 2010. Economics fit for a queen: a pessimistic assessment of its prospects. Prometheus: critical studies in innovation, 28 (3): 209-235.

Earl, Peter E., and Ti-Ching Peng. 2012. Brands of economics and the Trojan horse of pluralism. Review of Political Economy, 24 (3): 451-467.

Earl, Peter E., Ti-Ching Peng, and Jason Potts. 2007. Decision-rule cascades and the dynamics of speculative bubbles. Journal of Economic Psychology, 28 (3): 351-364.

Farmer, Roger E. A., and Jang-Ting Guo. 1994. Real business cycles and the animal spirits hypothesis. Journal of Economic Theory, 63 (1): 42-72.

Fiori, Stefano. 2011. Forms of bounded rationality: the reception and redefinition of Herbert A. Simon's perspective. Review of Political Economy, 23 (4): 587-612.

Goodhart, C. A. E. 2008. Risk, uncertainty, and financial stability. G. L. S. Shackle Memorial Lecture, LSE Financial Markets Group Paper Series SP 178. London, UK.

Hahn, Frank H. 1981. General equilibrium theory. In The crisis in economic theory, eds. Daniel Bell, and Irving Kristol. New York: Basic Books.

Hargreaves Heap, Shaun. 2009. Rub out the "not" in "not possible". Journal of Economic Methodology, 15 (2): 205-208.

Hong, Harrison, and Jeremy C. Stein. 2007. Disagreement and the stock market. Journal of Economic Perspectives, 21 (2): 109-128.

Kahneman, Daniel. 2003. Maps of bounded rationality: psychology for behavioral economics. American Economic Review, 93 (5): 1449-1475.

Kahneman, Daniel, and Amos Tversky. 1979. Prospect theory: an analysis of decision under risk. Econometrica, 47 (2): 263-291. 
Kirman, Alan P. 2011. Complex economics: individual and collective rationality. London: Routledge.

Lakatos, Imre. 1970. Falsification and the methodology of scientific research programmes. In Criticism and the growth of knowledge, eds. Imre Lakatos, and Alan Musgrave. Cambridge: Cambridge University Press, 59-89.

Lawson, Tony. 1997. Economics and reality. London: Routledge.

Lawson, Tony. 2009. The current economic crisis: its nature and the course of academic economics. Cambridge Journal of Economics, 33 (4): 759-777.

McCloskey, D. N. 1983. The rhetoric of economics. Journal of Economic Literature, 31 (2): 434-461.

Minsky, Hyman P. 1982. Inflation, recession, and economic policy. Brighton: Wheatsheaf.

Popper, Karl R. 1982. The open universe: an argument for indeterminism. London: Routledge.

Rabin, Matthew, and Richard H. Thaler. 2001. Anomalies: risk aversion. Journal of Economic Perspectives, 15 (1): 219-232.

Robbins, Lionel. 1932. An essay on the nature and significance of economic science. London: Macmillan.

Sent, Esther-Mirjam. 1998. The evolving rationality of rational expectations. Cambridge: Cambridge University Press.

Sent, Esther-Mirjam. 2004. Behavioural economics: how psychology made its (limited) way back into economics. History of Political Economy, 36 (4): 735-760.

Shiller, Robert J. 2000. Irrational exuberance. Princeton: Princeton University Press.

Shiller, Robert J. 2003. From efficient markets theory to behavioral finance. Journal of Economic Perspectives, 17 (1): 83-104.

Simon, Herbert A. 1955. A behavioral model of rational choice. Quarterly Journal of Economics, 69 (1): 99-118.

Tversky, Amos, and Daniel Kahneman. 1974. Judgment under uncertainty: heuristics and biases. Science, 185 (4157): 1124-1131.

Winter, Sidney G., Jr. 1964. Economic "natural selection" and the theory of the firm. Yale Economic Essays, 4 (1): 225-272.

Sheila C. Dow is emeritus professor of economics at the University of Stirling in Scotland and adjunct professor of economics at the University of Victoria in Canada. Her research interests lie in the history and methodology of economic thought, and in the theory of money, banking and monetary policy. Her current work focuses on developing applications of Keynesian epistemology and on the evolution of central banking. Her publications include Economic methodology: an inquiry (Oxford University Press, 2002), and Foundations for new economic thinking (Palgrave Macmillan, 2012).

Contact e-mail: <s.c.dow@stir.ac.uk> 